\title{
Effects of granulocyte colony-stimulating factor on rabbit carotid and porcine heart models of chronic obliterative arterial disease
}

\author{
ZHAOHUI HU ${ }^{1 *}$, ZHISONG CHEN $^{1 *}$, YIPING WANG ${ }^{1}$, JINFA JIANG $^{1}$, GARY TSE $^{2,3}$, \\ WENJUN XU ${ }^{1}, J_{U N B O} \mathrm{GE}^{4}$ and BING SUN ${ }^{1}$ \\ ${ }^{1}$ Department of Cardiovascular Diseases, Tongji Hospital of Tongji University, Shanghai 200065; \\ ${ }^{2}$ Department of Medicine and Therapeutics; ${ }^{3} \mathrm{Li} \mathrm{Ka}$ Shing Institute of Health Sciences, \\ Chinese University of Hong Kong, Hong Kong, SAR; ${ }^{4}$ Shanghai Institute of Cardiovascular Diseases, \\ Zhongshan Hospital, Fudan University, Shanghai 200032, P.R. China
}

Received May 23, 2016; Accepted March 1, 2019

DOI: $10.3892 / \mathrm{mmr} .2019 .10120$

\begin{abstract}
Previous studies suggest that granulocyte colony-stimulating factor (G-CSF) can promote bone marrow derived progenitor cells to mediate cardiovascular repair, potentially reversing mechanical dysfunction in chronic ischaemic heart disease and post myocardial infarction. Two models were used in the present study both using a surgical ameroid constrictor to induce arterial stenosis. The first model used the carotid artery of rabbits. They were divided into high fat diet (inducing atherosclerosis) or normal fat diet (control) groups. Each was subdivided into surgical exposure group without constrictor, ameroid constrictor receiving normal saline or receiving G-CSF $15 \mu \mathrm{g} / \mathrm{kg} / \mathrm{day}$. Endothelial markers of endothelial nitric oxide synthase and endothelin 1 were increased by the use of ameroid constrictor in both atherosclerotic and non-atherosclerotic mice, however were not further altered by G-CSF. Scanning electron microscopy indicated that ameroid constrictor application altered endothelial morphology from an oval shape to a round shape and this was more prominent in the atherosclerotic compared with the non-atherosclerotic group. G-CSF injection increased the number of endothelial cells in all groups. The second model used the left coronary artery of pigs. They were equally divided into following groups, receiving normal saline (control), G-CSF $2.5 \mu \mathrm{g} / \mathrm{kg} /$ day (low dose), $5 \mu \mathrm{g} / \mathrm{kg} /$ day (medium dose) and $10 \mu \mathrm{g} / \mathrm{kg} / \mathrm{day}$ (high dose) for 5 days. G-CSF at a low or high dose worsened intimal hyperplasia however at a medium
\end{abstract}

Correspondence to: Dr Bing Sun, Department of Cardiovascular Diseases, Tongji Hospital of Tongji University, 389 Xincun Road, Shanghai 200065, P.R. China

E-mail: woowoocncn@163.com

*Contributed equally

Key words: granulocyte colony-stimulating factor, chronic obliterative arterial disease, ischaemic heart disease, atherosclerosis, ameroid constrictor dose improved it. In conclusion, G-CSF had no effect in a rabbit carotid artery model of atherosclerosis. Its effects on the porcine heart were dose-dependent; arterial disease worsened at a low or high dose, but improved at a medium dose.

\section{Introduction}

Stem cell-based therapy has been demonstrated as a good option for cardiac repair following myocardial infarction (MI). Previous clinical trials have demonstrated efficacy using a traumatic method of bone marrow aspiration, culture of the bone marrow stem cells and intracoronary infusion of this end-product (1). Another less invasive option is to use granulocyte colony-stimulating factor (G-CSF) to mobilize bone marrow-derived progenitor cells to undertake tissue repair (2). The advantage of this technique is that it is less traumatic, requiring only subcutaneous injections. However, the results on its therapeutic efficacy have thus far been conflicting. In the FIRSTLINE-AMI study, subcutaneous injection of G-CSF shortly after successful primary percutaneous coronary intervention (PCI) in patients suffering from acute ST elevation MI was demonstrated to mobilize mononuclear blood stem cells (3). This resulted in enhanced resting wall thickening of the infarcted myocardium, improvement of wall motions and systolic function without apparent re-stenosis. Further studies have demonstrated a good safety profile without reports of adverse effects $(2,4,5)$. However, the REVIVAL-2 study demonstrated that delayed application of G-CSF 5 days after successful PCI did not significantly reduce infarct size or improve left ventricular function (6). Furthermore, usage of G-CSF in acute MI may be a double-edged sword, due to the fact that it may paradoxically reduce the migratory capacity of bone marrow-derived progenitor cells into the ischaemic myocardium and thus there is a need to optimize the cytokine profile with other agents to ensure their successful migration (7).

Animal studies have proven useful in the study of the properties of G-CSF. A previous study used a porcine model of ischaemic heart disease to demonstrate improvement in cardiac contractile function in chronic myocardial ischaemia after G-CSF administration (8). Whilst its efficacy in reversing mechanical dysfunction in the heart has been observed, the 
potential benefits in chronic obliterative arterial disease remain to be fully investigated. Thus, the present study aimed to investigate the effects of G-CSF in a novel rabbit model of chronic obliterative arterial disease, which was generated by clamping the carotid artery using a surgical ameroid constrictor. These results were compared with those of an established porcine model of ischamic heart disease generated by clamping of the left coronary artery also using this constrictor.

\section{Materials and methods}

Animal model 1. A novel rabbit model of chronic obliterative arterial disease was produced by clamping the right carotid artery using an ameroid constrictor. The current study was approved by the Animal Welfare Ethics Committee of the Tongji Hospital of Tongji University. A total of $36 \mathrm{New}$ Zealand rabbits were used (male, six months old male weight 2-3 kg; SPF grade Ivl; Experimental Animal Centre, Tongji Hospital). The animals were housed at $22 \pm 1^{\circ} \mathrm{C}$ and $50-60 \%$ relative humidity with a 12-h light/dark cycle. They were divided into 2 groups, with one group being fed a high fat diet for two months to induce atherosclerosis (AS), whereas the other group was fed a normal fat diet, acting as the control group (CON). Each group was further subdivided into three groups: Sham group (carotid arteries surgically exposed but no ameroid constrictors were applied; SHAM), ameroid constrictor group receiving hypodermic saline $(0.5 \mathrm{ml}$ daily for 5 days; NS) and ameroid constrictor group receiving G-CSF (15 $\mu$ g.kg ${ }^{-1}$ daily; Shanghai 3D Biotechnology Co., Ltd.). The 6 groups were therefore: AS-SHAM, AS-NS, AS-G-CSF; CON-SHAM, CON-NS and CON-G-CSF.

Ultrasound studies of the carotid arteries. The following parameters were measured using Doppler ultrasound Vevo770 Imaging system (VisualSonics, Inc., Toronto, ON, Canada) at four different time points (prior to surgery and 3,5 or 7 weeks after surgery): Peak systolic flow velocity, resistance index and the end-diastolic velocity. Stenosis rate was calculated by (difference in diameters between left and right carotid arteries)/(left carotid artery).

Reverse transcription-quantitative polymerase chain reaction $(R T-q P C R)$. RNA was extracted and purified from the proximal portion of the right carotid artery using TRIzol (Invitrogen; Thermo Fisher Scientific, Inc., Waltham, MA, USA). Quantification was achieved using a spectrophotometer. A total of $2 \mu \mathrm{g}$ RNA was used as a template for a RT-qPCR with random hexamers (Toyobo Life Science, Osaka, Japan) as primers. Then, $10 \mu \mathrm{l}$ cDNA was purified with an additional ethanol washing step. Levels of mRNA were quantified by RT-qPCR using a Rotor-Gene 2000 machine (Corbett Research, Mortlake, Australia). The results were presented as gene copy numbers relative to GAPDH. The primers were used as follows: Endothelin 1 (ET-1), upstream, 5'-CTCTCTGCTGTTGGTGGCTTT-3' and downstream 5'-TGGGTTTTCCGCTCCTGT-3'; endothelial nitric oxide synthase (eNOS), upstream 5'-AGGCCTCCTGTG AGACTTTC-3' and downstream 5'-AAGGAGTCGAGG ACTGGATG-3'; GAPDH, upstream 5'-CCACTTTGTGAA GCTCATTTCCT-3' and downstream 5'-TCGTCCTCCTCT GGTGCTCT-3'.
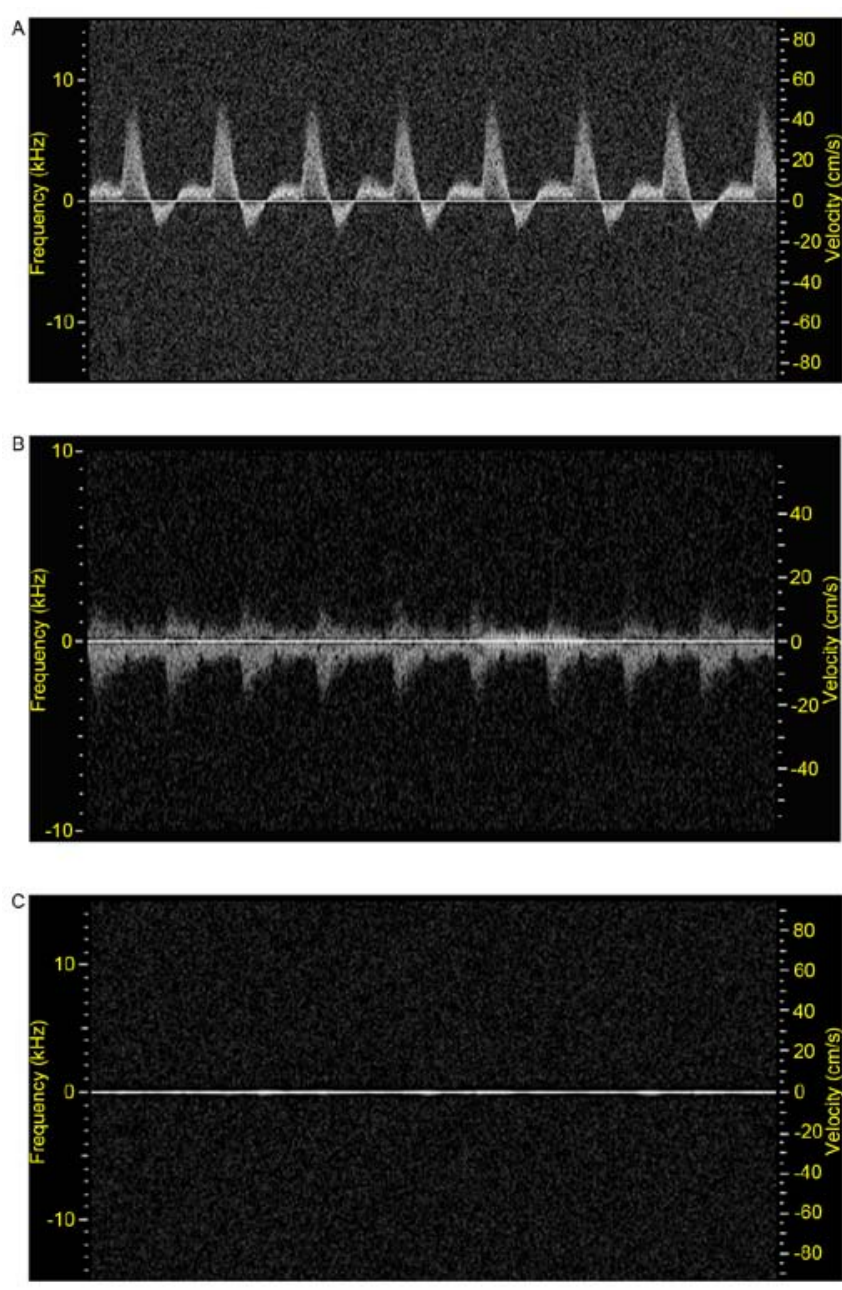

Figure 1. Pulse-wave Doppler ultrasound flow (A) before, (B) 3 weeks and (C) 5 weeks following ameroid constrictor placement around right common carotid artery. Pre-surgery, the peak blood flow velocity of right common carotid artery) was evident, however, the peak flow velocity was markedly reduced at 3 weeks after the operation, and was not observed at 5 weeks.

Scanning electron microscopy. The appearance of the endothelium of the rabbit carotid arteries close to the site of ameroid constrictor application was studied using a scanning electron microscope (HITACHI-S520; Hitachi, Tokyo, Japan).

Animal model 2. A well-established porcine model of chronic ischemic heart disease was also used in the present study, which involved clamping the left coronary artery using an ameroid constrictor. A total of 24 pigs (male, 1 year old, weight $\sim 40 \mathrm{~kg}$; Beijing University of Agriculture, China) The animals were housed in a cage with straw at $22 \pm 1^{\circ} \mathrm{C}$ and $50-60 \%$ relative humidity with a 12 -h light/dark cycle and water and food ad libitum. They were equally divided into four groups, receiving normal saline $0.5 \mathrm{ml}$ (control), G-CSF $2.5 \mu \mathrm{g} \cdot \mathrm{kg}^{-1}$.day ${ }^{-1}$ (low dose), $5 \mu \mathrm{g} \cdot \mathrm{kg}^{-1} \cdot \mathrm{day}^{-1}$ (medium dose) and $10 \mu \mathrm{g} \cdot \mathrm{kg}^{-1} \cdot \mathrm{day}^{-1}$ (high dose) for 5 days. G-CSF was diluted using normal saline.

Histology and immunohistochemistry. In the porcine model, the proximal portion of occluded coronary arteries were obtained four weeks after the operation, which allowed effects of G-CSF on histology to be determined. Hematoxylin and eosin (H\&E) staining was used to examine angiogenesis and 
Table I. Doppler flow parameters after 3 weeks.

\begin{tabular}{llrrrrrr}
\hline Sample & \multicolumn{1}{c}{ Group } & AS-SHAM & AS-NS & AS-G-CSF & CON-SHAM & CON-NS & CON-G-CSF \\
\hline Opposite & D $(\mathrm{cm})$ & $2.01 \pm 0.13$ & $2.00 \pm 0.095$ & $2.0 \pm 0.09$ & $1.82 \pm 0.16$ & $1.91 \pm 0.11$ & $1.76 \pm 0.05$ \\
& $\mathrm{~V}_{\max }(\mathrm{cm} / \mathrm{s})$ & $34.11 \pm 3.21$ & $42.65 \pm 2.08$ & $44.23 \pm 2.80$ & $42.70 \pm 3.66$ & $45.52 \pm 4.95$ & $43.47 \pm 4.24$ \\
& EDV $(\mathrm{cm} / \mathrm{s})$ & $11.25 \pm 1.34$ & $17.48 \pm 1.27$ & $13.47 \pm 1.10$ & $18.99 \pm 2.23$ & $19.13 \pm 2.50$ & $14.34 \pm 1.37$ \\
& RI & $0.67 \pm 0.18$ & $0.59 \pm 0.20$ & $0.78 \pm 0.17^{\mathrm{a}}$ & $0.55 \pm 0.26$ & $0.58 \pm 0.25$ & $0.66 \pm 0.03^{\mathrm{b}}$ \\
Proximal & $\mathrm{D}(\mathrm{cm})$ & $1.80 \pm 0.11$ & $1.53 \pm 0.12$ & $1.33 \pm 0.14$ & $1.81 \pm 0.12$ & $1.81 \pm 0.14$ & $1.64 \pm 0.23$ \\
& $\mathrm{~V}_{\max }(\mathrm{cm} / \mathrm{s})$ & $33.63 \pm 3.57$ & $28.31 \pm 3.89$ & $25.28 \pm 7.02$ & $45.00 \pm 6.76$ & $54.32 \pm 5.44^{\mathrm{c}}$ & $33.75 \pm 9.85^{\mathrm{b}}$ \\
& EDV $(\mathrm{cm} / \mathrm{s})$ & $12.44 \pm 1.80$ & $11.6 \pm 1.89$ & $9.89 \pm 2.91$ & $19.00 \pm 3.47$ & $19.44 \pm 1.77^{\mathrm{d}}$ & $12.28 \pm 3.69$ \\
& RI & $0.62 \pm 0.21$ & $0.64 \pm 0.05$ & $0.66 \pm 0.05$ & $0.57 \pm 0.17$ & $0.81 \pm 0.05^{\mathrm{d}}$ & $0.75 \pm 0.06$ \\
& Stenosis rate $(\%)$ & 0 & $33.24 \pm 0.06$ & $49.51 \pm 0.13$ & 0 & $8.55 \pm 0.04^{\mathrm{d}}$ & $42.13 \pm 0.10^{\mathrm{a}}$ \\
& & & & & & &
\end{tabular}

${ }^{\mathrm{a}} \mathrm{P}<0.01$ and ${ }^{\mathrm{b}} \mathrm{P}<0.05 \mathrm{G}-\mathrm{CSF}$ vs. control; ${ }^{\mathrm{c}} \mathrm{P}<0.01$ and ${ }^{\mathrm{d}} \mathrm{P}<0.05$, VS between atherosclerosis or none. $\mathrm{D}$, diameter; $\mathrm{V}_{\max }$, maximum velocity; EDV, end diastolic velocity; RI, resistance index; AS atherosclerosis; NS, ameroid constrictor group receiving saline; G-CSF, granulocyte colony-stimulating factor; $\mathrm{CON}$, control.

Table II. Frequency of complete obliteration among the groups after 5 and 7 weeks.

\begin{tabular}{lcccccc}
\hline Group & AS-SHAM & AS-NS & AS-G-CSF & CON-SHAM & CON-NS & CON-G-CSF \\
\hline Week 5 & 0 & 2 & $5^{\mathrm{a}}$ & 0 & 1 & 2 \\
Week 7 & 0 & $4^{\mathrm{a}}$ & $6^{\mathrm{b}}$ & 0 & 3 & $5^{\mathrm{a}}$ \\
\hline
\end{tabular}

${ }^{a} \mathrm{P}<0.05$ and ${ }^{\mathrm{b}} \mathrm{P}<0.01$ vs. sham operation group. AS, atherosclerosis; NS, ameroid constrictor group receiving saline; G-CSF, granulocyte colony-stimulating factor; $\mathrm{CON}$, control.

quantified using a Leica Qwin V3 imaging system (Leica Microsystems GmbH, Wetzlar, Germany). Mallory stain was used to study collagen content. Immunohistochemical staining were used to examine vascular endothelial growth factor (VEGF) and tumor necrosis factor (TNF)- $\alpha$, which reflected angiogenesis and inflammation, respectively.

Statistical analysis. All data were presented as mean \pm standard error. Fisher's exact test was used as appropriate using SPSS (version 11.5; SPSS, Inc., Chicago, IL, USA). P<0.05 was considered to indicate a statistically significant difference.

\section{Results}

\section{Carotid artery in rabbit model}

Ultrasound assessment of the occluded right carotid artery. Ultrasound was used for assessing the functional status of the right carotid artery of rabbit hearts. Firstly, B-mode ultrasonography was used to determine real-time information on the lumen and vessel wall $(9,10)$. Secondly, Doppler imaging was used to determine flow parameters (Fig. 1). Three weeks after the operation, the right carotid artery developed stenosis (Table I). Five weeks later, total occlusion was observed in all groups at different rates (Table II).

Assessment of endothelial function using RT-qPCR. RNA was extracted from the proximal portion of the right carotid arteries in the different groups (Fig. 2). Expression indices of endothelial nitric oxide synthase (eNOS) in the AS-SHAM and CON-SHAM groups were $0.85 \pm 0.11$ and $0.91 \pm 0.12$, respectively. They were increased to $2 \pm 0.206$ and $1.89 \pm 0.33$ for the AS-NS and CON-NS groups. However, these values were not significantly different from the values in the presence of G-CSF $(2.14 \pm 0.30$ and $1.94 \pm 0.32$ for AS-G-CSF and CON-G-CSF). The expression levels of ET-1 were $1.3 \pm 0.17$ and 1.5 \pm 0.25 (AS-SHAM and CON-SHAM), 0.65 \pm 0.08 and $0.67 \pm 0.09$ (AS-NS and CON-NS) and $0.57 \pm 0.05$ and $0.59 \pm 0.05$ (AS-G-CSF and CON-G-CSF). There were no significant difference between the groups treated with normal saline compared with those treated with G-CSF.

Assessment of endothelial morphology using scanning electron microscopy. The morphology of endothelial cells of the proximal carotid artery were assessed using scanning electron microscopy (Fig. 3). In the AS-SHAM and CON-SHAM groups, endothelial cells took on an oval shape, which was due to linear blood flow within the artery. When compared with the CON-SHAM group, the AS-SHAM group, the endarterium developed a rougher morphology with a smaller number of endothelial cells, and had a more shrunken image with tiny lipid droplets. With application of the ameroid constrictor, this morphology was changed to one of roundness due to the turbulent flow distal to the site of occlusion. Such a change was more prominent in the AS-SHAM than CON-SHAM group. The number of endothelial cells increased after G-CSF injections. 
Relative expression of eNOS vs. GAPDH

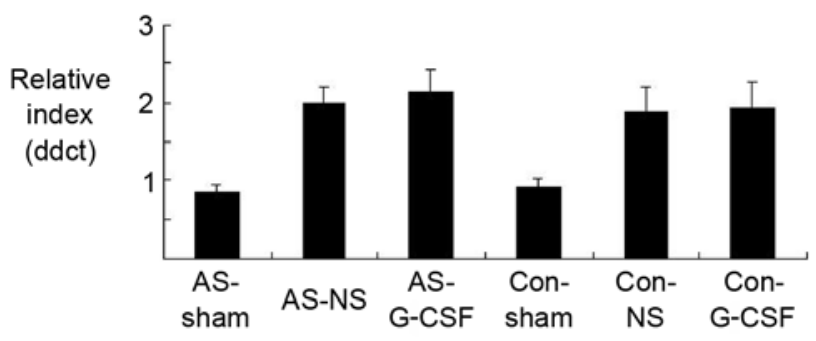

Relative expression of ET-1 vs. GAPDH

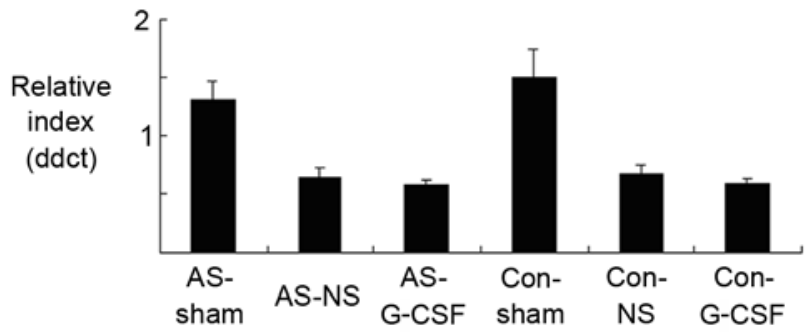

Figure 2. G-CSF administration did not result in a significant difference in eNOS and ET-1 gene expression. The proximal carotid near the constrictor or the same site was harvested for reverse transcription-quantitative polymerase chain reaction analysis from the rabbits for all groups studied. In addition, no changes after high fat diet administration were observed ( $\mathrm{n}=6$ per group). G-CSF, granulocyte colony-stimulating factor; eNOS, endothelial nitric oxide synthase; ET-1, endothelin 1; AS, atherosclerosis; NS, ameroid constrictor group receiving saline; Con, control.
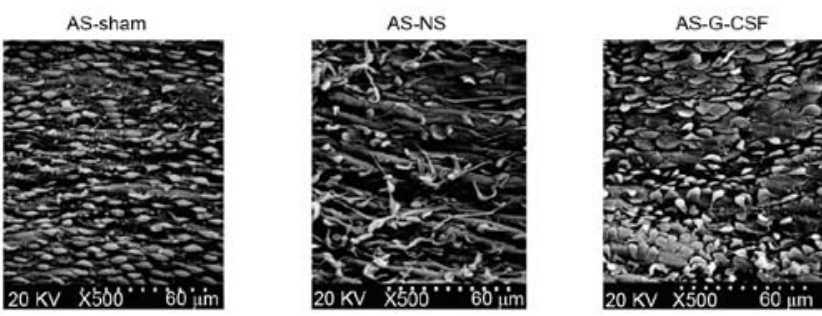

Con-sham

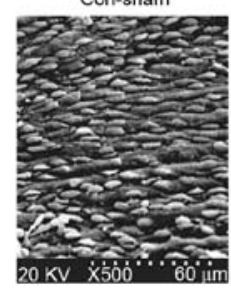

Con-NS

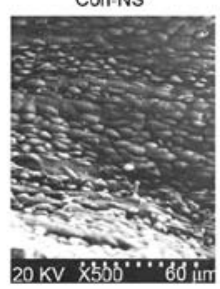

Con-G-CSF

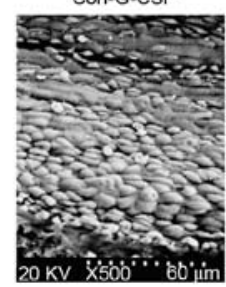

Figure 3. Endothelial cells under scanning electron microscopy. AS, atherosclerosis; NS, ameroid constrictor group receiving saline; Con, control; $\mathrm{G}-\mathrm{CSF}$, granulocyte colony-stimulating factor.

\section{Left coronary artery in swine model}

Histological studies to determine effects of varying dosages of $G-C S F$. Four weeks after the operation, histological studies exhibited intimal proliferation together with eccentric narrowing in the left coronary arteries (Fig. 4). H\&E staining indicated varying degrees of intimal hyperplasia in the different groups. Intimal hyperplasia was more severe
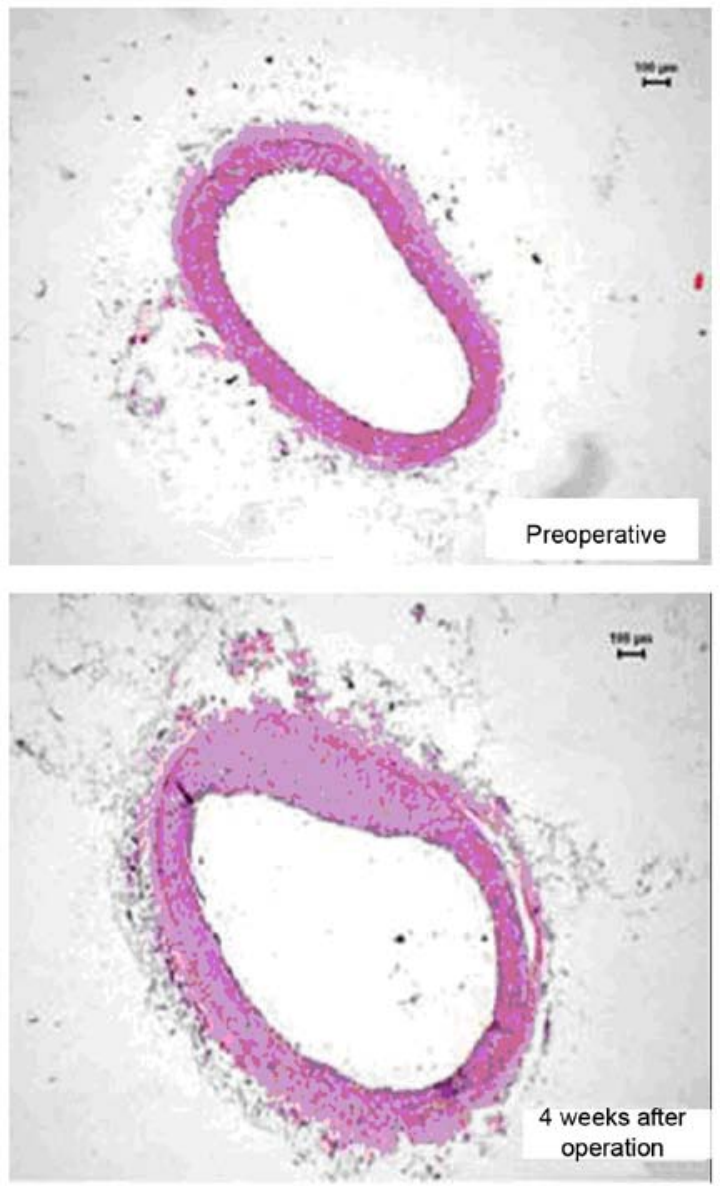

Figure 4. The proximal endangium near the constrictor (hematoxylin and eosin stain; magnification, $\mathrm{x} 40$ ).

in the low and high dose G-CSF groups compared with the control group, whereas it was less severe in the medium dose group compared with the control (Fig. 5). The areas of tunica intima and vessel lumen were analyzed using Leica Qwin Plus Graphic Processing System, which allowed proliferation area to be calculated (Fig. 6).

Mallory's trichrome staining of the proximal coronary artery indicated significantly smaller amounts of collagen in the medium and high dose groups compared with the control group. However, there was no significant difference between the low dose and control group (Fig. 7).

Effects on VEGF and TNF-a. In order to examine the role of angiogenesis and inflammation, immunohistochemistry was used to determine the expression of VEGF and TNF- $\alpha$. G-CSF exerted a dose-dependent effect on VEGF and TNF- $\alpha$, increasing them both at increasing concentrations (Fig. 8).

\section{Discussion}

G-CSF has exhibited some efficacy in reversing mechanical dysfunction in chronic ischaemic heart disease and following MI. A previous studies demonstrated its safety in humans, however results regarding its therapeutic effects remain conflicting (10). A previous study failed to demonstrate improvement in ventricular function post MI using G-CSF 

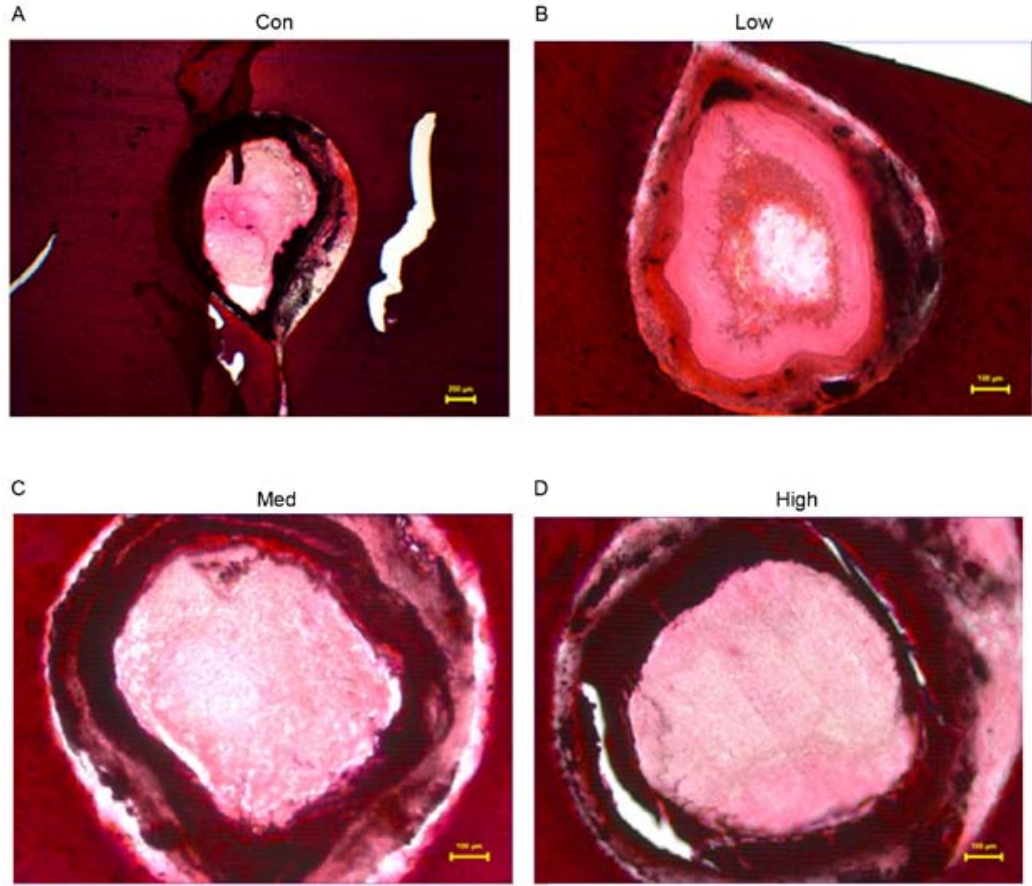

D

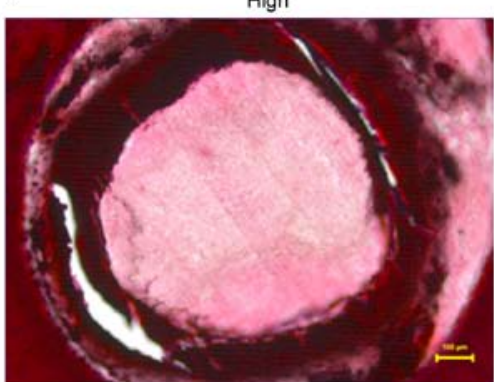

Figure 5. Intimal hyperplasia in different G-CSF treatment groups. (A) Control group (NS $0.5 \mathrm{ml} / \mathrm{kg} / \mathrm{day}$ ), (B) the low dosage group (G-CSF $2.5 \mathrm{mg} / \mathrm{kg} / \mathrm{day}$ ), (C) medium dosage group (G-CSF $5 \mathrm{mg} / \mathrm{kg} / \mathrm{day}$ ) and (D) high dosage group (G-CSF $10 \mathrm{mg} / \mathrm{kg} / \mathrm{day}$ ) (hematoxylin and eosin stain; magnification, x40). G-CSF, granulocyte colony-stimulating factor; NS, ameroid constrictor group receiving saline; Con, control.

A

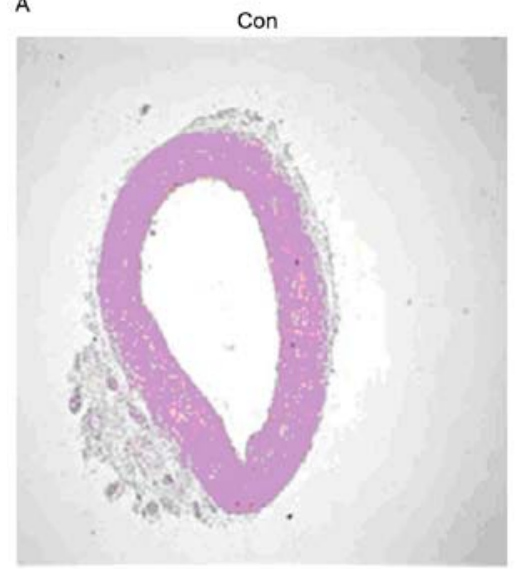

C

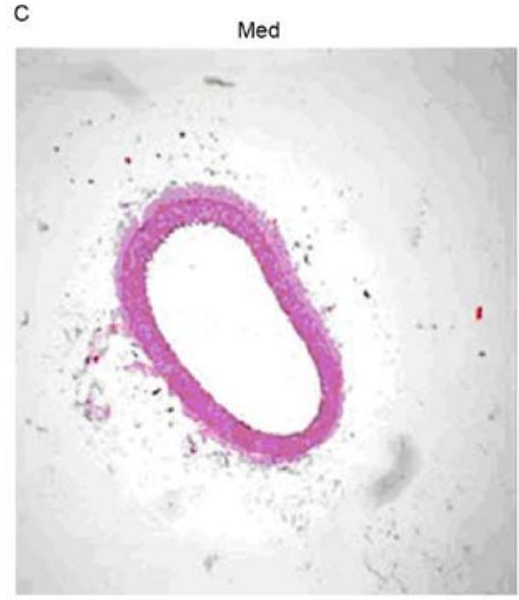

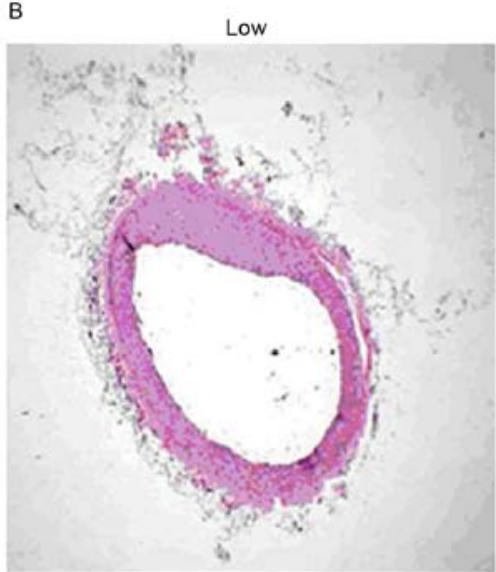

D

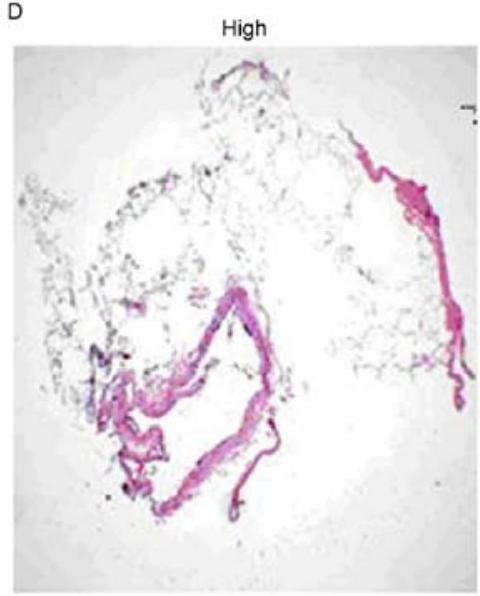

Figure 6. Local endarterium of the proximal artery near the constrictor. (A) Control group (NS $0.5 \mathrm{ml} / \mathrm{kg} / \mathrm{day}$ ), (B) the low dosage group (G-CSF $2.5 \mathrm{mg} / \mathrm{kg} / \mathrm{day}$ ), (C) medium dosage group (G-CSF $5 \mathrm{mg} / \mathrm{kg} / \mathrm{day}$ ) and (D) high dosage group (G-CSF $10 \mathrm{mg} / \mathrm{kg} /$ day); hematoxylin and eosin stain; magnification, x40; NS, ameroid constrictor group receiving saline; G-CSF, granulocyte colony-stimulating factor; Con, control. 

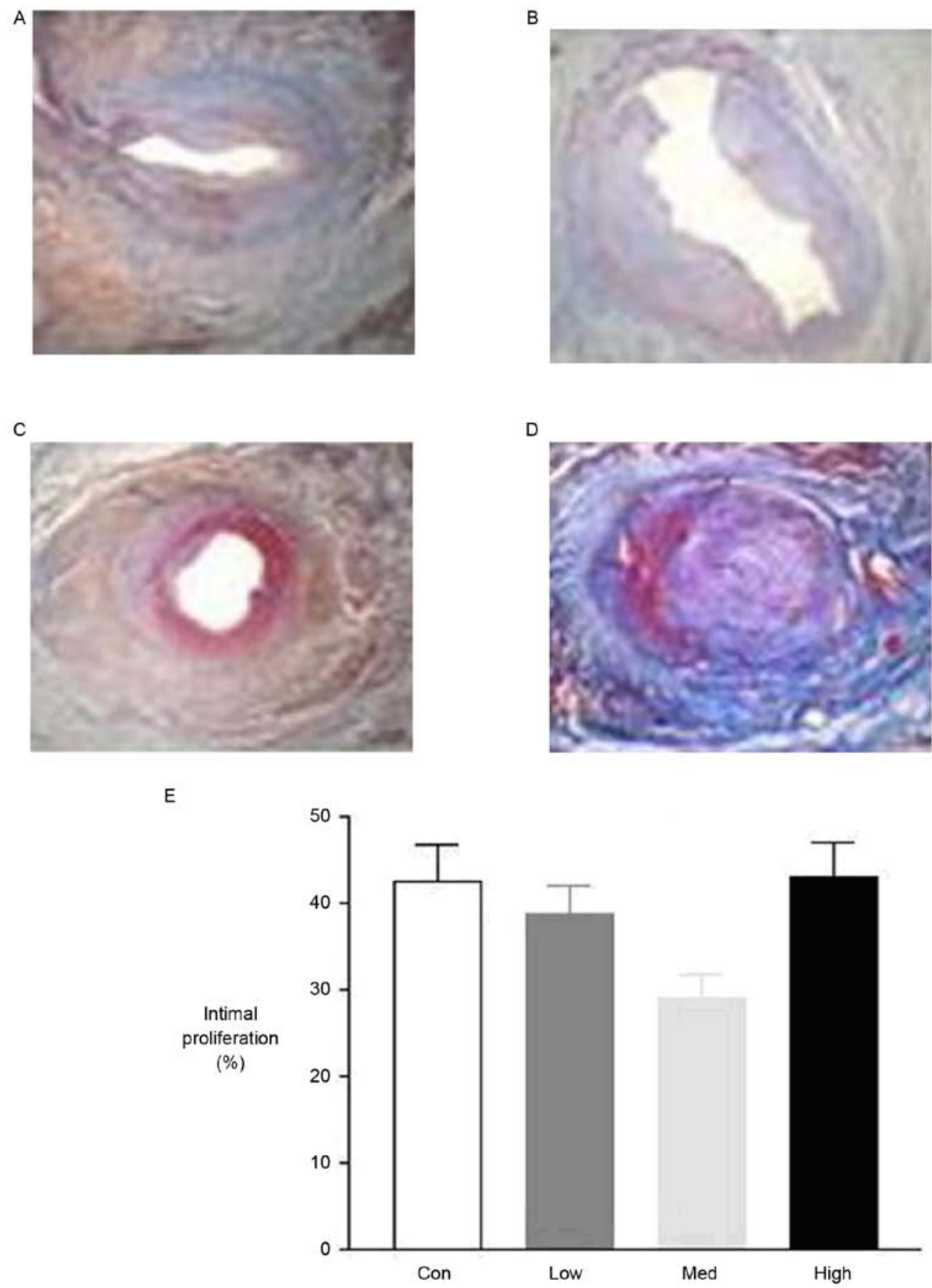

Figure 7. The pathology of different dosage groups. (A) Control group (NS $0.5 \mathrm{ml} / \mathrm{kg} / \mathrm{day}$ ), (B) the low dosage group (G-CSF $2.5 \mathrm{mg} / \mathrm{kg} / \mathrm{day}$ ), (C) medium dosage group (G-CSF $5 \mathrm{mg} / \mathrm{kg} / \mathrm{day}$ ) and (D) high dosage group (G-CSF $10 \mathrm{mg} / \mathrm{kg} / \mathrm{day}$ ); (A-C) hematoxylin and eosin and (D) Mallory's trichrome staining; magnification, x400. Quantification is presented in (E). NS, ameroid constrictor group receiving saline; G-CSF, granulocyte colony-stimulating factor; Con, control.

when compared with the control group (11), in contrast to other studies in which improved left ventricular systolic function was observed $(4,5)$. However, G-CSF was demonstrated to reduce the migratory capacity of bone marrow-derived progenitor cells into the ischaemic myocardium (7). In addition, patients suffering from coronary artery disease responded to G-CSF by exhibiting increased numbers of endothelial progenitor cells (EPCs) and higher expression of the chemokine receptor CXCR4, which directed EPCs to ischaemic tissue (12). However, increased mobilization did not equate to reversal of damage, no significant improvement in wall motion, perfusion or exercise duration after G-CSF use was observed (13). However, intra-coronary infusion of G-CSF did mobilize peripheral blood stem cells and improved ejection fraction in patients with acute MI although not in those with chronic ( $\geq 6 \pm 1.2$ months) MI (14).

The mechanism of action of G-CSF remains to be fully elucidated. Different animal models have been useful for modelling the molecular mechanisms of human diseases ADDIN EN.CITE (15-35), resulting in translational insights (36-41). Mice and rats have been used because of their amenability to genetic modification, as demonstrated by the study of ion channel mutations on cardiovascular physiology (42-44). The effects of increased oxidative stress on endothelial function have been studied in diabetic mice and spontaneously hypertensive rats, modelling human cardio-metabolic disorders (45-57). Larger 
A

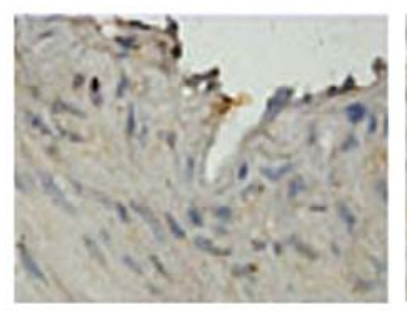

B

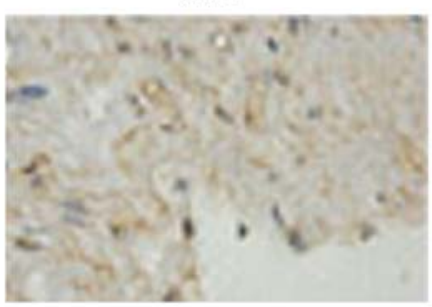

C

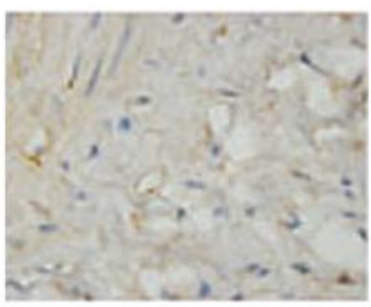

D

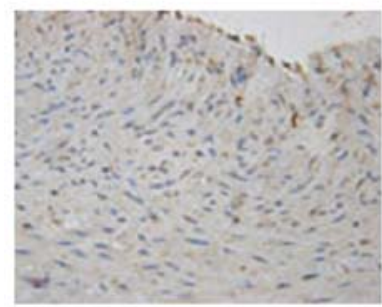

E

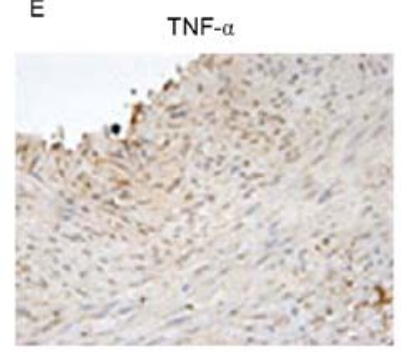

F

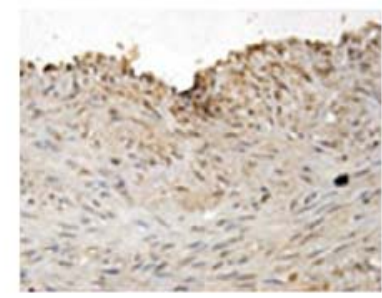

Figure 8. VEGF in the (A) low dosage group (G-CSF $2.5 \mathrm{mg} / \mathrm{kg} / \mathrm{day}$ ), (B) medium dosage group (G-CSF $5 \mathrm{mg} / \mathrm{kg} / \mathrm{day})$ and (C) high dosage group (G-CSF $10 \mathrm{mg} / \mathrm{kg} / \mathrm{day}$ ). TNF- $\alpha$ in the (D) low dosage group (G-CSF $2.5 \mathrm{mg} / \mathrm{kg} / \mathrm{day}$ ), (E) medium dosage group (G-CSF $5 \mathrm{mg} / \mathrm{kg} / \mathrm{day}$ ) and (F) high dosage group (G-CSF $10 \mathrm{mg} / \mathrm{kg} / \mathrm{day})$. Immunohistochemistry images, magnification x1,000). VEGF, vascular endothelial growth factor; G-CSF, granulocyte colony-stimulating factor; TNF- $\alpha$, tumor necrosis factor $\alpha$; Con, control.

animals such as guinea pigs and pigs have haemodynamic parameters more similar to humans, and are therefore useful for studying flow properties, however it remains a challenge to study using methods involving large machines, such as cardiac magnetic resonance imaging $(34,35)$. In a rat model, inhibition of neointimal formation and increased re-endothelialisation of injured arteries has been observed, potentially via a direct effect on the heart and the arteries (58). In the current study, two animal models were employed by applying ameroid surgical constrictors to the right carotid artery of rabbits or to the left coronary artery of pigs.

In the rabbit model, a high fat diet led to the development of atherosclerosis, a chronic inflammatory disease (59). The number of endothelial cells increased after G-CSF injection at a dose of $15 \mu \mathrm{g} / \mathrm{kg} / \mathrm{day}$ as demonstrated using scanning electron microscopy. However, there was no change in endothelial function assessed using RT-qPCR for the endothelial markers endothelial nitric oxide synthase and ET-1. Whether or not G-CSF is protective in atherosclerosis remains controversial. At a dose of $10 \mu \mathrm{g} / \mathrm{kg} / \mathrm{day}$, $\mathrm{G}-\mathrm{CSF}$ has been demonstrated to worsen atherosclerosis in apolipoprotein E-deficient mice (60), however by contrast, at a high dose of $100 \mu \mathrm{g} / \mathrm{kg} / \mathrm{day}$, it prevented progression of atherosclerosis in heritable hyperlipidemic rabbits and following vascular injury induced by angioplasty balloon in rabbits (61). In an iliac artery injury model of rabbits, G-CSF at a dose of $70 \mu \mathrm{g} /$ day mobilized vascular progenitor cells, which induced neointimal overgrowth at the stented vessels and enhanced endothelial healing was observed when drug-eluting stent was used when compared with a bare metal stent (62). In a rat model, G-CSF increased the number of mononuclear cells in the circulation, increased endothelial adhesion markers and re-endothelialization of the denuded vessels, which resulted in parallel reductions in inflammation in the vessel wall (63).

The present study in porcine hearts observed increasing intimal hyperplasia after low $(2.5 \mu \mathrm{g} / \mathrm{kg} / \mathrm{day})$ or high (10 $\mu \mathrm{g} / \mathrm{kg} /$ day) doses of G-CSF. Furthermore, the mobilization of bone marrow-derived progenitor cells using G-CSF resulted in increased endothelial expressions of VEGF and TNF- $\alpha$, markers of angiogenesis and inflammation, respectively, as assessed using immunohistochemistry and western blot analysis. G-CSF has pleotropic effects, and is capable of inducing hyperplasia, angiogenesis and inflammation (62). Whether it is beneficial or harmful depends on the relative contributions to the above processes. In the present study, intimal hyperplasia was increased in chronic obliterative arterial disease, in contrast to observations in humans where G-CSF was demonstrated to be effective in acute as opposed to chronic ( $\geq 6 \pm 1.2$ months \pm 1.2 ) MI (14). Other beneficial effects of G-CSF have been reported in rats, where a neuroprotective role was demonstrated in transient middle cerebral artery occlusion (64). However, G-CSF can be ineffective or potentially harmful. For example, experiments in a swine model of ischaemia-reperfusion injury indicated that G-CSF accelerated angiogenesis, reduced fibrosis however did not improve either ejection fraction or end-diastolic volume (65). Furthermore, intramyocardial VEGF gene transfer followed by bone marrow stem cell mobilization using G-CSF was safe however did not significantly improve myocardial perfusion as assessed by single photon emission computerized tomography (66). G-CSF aggravated in-stent re-stensosis, which was partly dependent on VEGF and STAT-3, although this may be reduced by using a sirolimus drug-eluting stent (67). 
In conclusion, the present study identified that: i) G-CSF did not alter endothelial function in the carotid artery of a rabbit model of atherosclerosis; ii) its effects on chronic ischaemic heart disease in pigs are dose-dependent, worsening intimal hyperplasia when used at a low or high dose, however improving it at a medium dose. Therefore, its therapeutic role warrants further attention.

\section{Acknowledgements}

The authors would like to thank Dr Dingzhiwen of the Department of Cardiology, Shanghai Institute of Cardiovascular Diseases, Zhongshan Hospital (Shanghai, China), for providing the facilities for operations on animals and analysis on tissue pathology.

\section{Funding}

Professor Gary Tse was supported by the Biotechnology and Biological Sciences Research Council Doctoral Training Award at the University of Cambridge. In addition, the current study was supported by grants from the National 973 Program of China (grant no. 2007CB512003), National Natural Science Foundation of China (grant no. 81300150) and Science and Technology Commission of Shanghai (grant no. 074107020).

\section{Availability of data and materials}

The datasets used and/or analyzed during the current study are available from the corresponding author on reasonable request.

\section{Authors' contributions}

The manuscript was written with contributions from all authors. All authors have given approval to the final version of the manuscript. $\mathrm{ZH}$ performed the research and experiments. ZC, YW, JJ, GT, WX, JG and BS contributed to data analysis. $\mathrm{ZH}$ and $\mathrm{ZC}$ were responsible for the overall project design and manuscript organization.

\section{Ethics approval and consent to participate}

The present study was approved by the Animal Welfare Ethics Committee of the Tongji Hospital of Tongji University and the approval number was 2017-DW-006.

\section{Patient consent for publication}

Not applicable.

\section{Competing interests}

The authors declare no conflict of interest.

\section{References}

1. Traverse JH, McKenna DH, Harvey K, Jorgenso BC, Olson RE, Bostrom N, Kadidlo D, Lesser JR, Jagadeesan V, Garberich R and Henry TD: Results of a phase 1, randomized, double-blind, placebo-controlled trial of bone marrow mononuclear stem cell administration in patients following ST-elevation myocardial infarction. Am Heart J 160: 428-434, 2010.
2. Ince H, Petzsch M, Kleine HD, Eckard H, Rehders T, Burska D, Kische S, Freund M and Nienaber CA: Prevention of left ventricular remodeling with granulocyte colony-stimulating factor after acute myocardial infarction: Final 1-year results of the front-integrated revascularization and stem cell liberation in evolving acute myocardial infarction by granulocyte colony-stimulating factor (FIRSTLINE-AMI) trial. Circulation 112 (9 Suppl): I73-I80, 2005.

3. Ince H, Petzsch M, Kleine HD, Schmidt H, Rehders T, Körber T, Schümichen C, Freund M and Nienaber CA: Preservation from left ventricular remodeling by front-integrated revascularization and stem cell liberation in evolving acute myocardial infarction by use of granulocyte-colony-stimulating factor (FIRSTLINE-AMI). Circulation 112: 3097-3106, 2005.

4. Takano H, Hasegawa H, Kuwabara Y, Nakayama T, Matsuno K, Miyazaki Y, Yamamoto M, Fujimoto Y, Okada H, Okubo S, et al: Feasibility and safety of granulocyte colony-stimulating factor treatment in patients with acute myocardial infarction. Int J Cardiol 122: 41-47, 2007.

5. Valgimigli M, Rigolin GM, Cittanti C, Malagutti P, Curello S, Percoco G, Bugli AM, Della Porta M, Bragotti LZ, Ansani L, et al: Use of granulocyte-colony stimulating factor during acute myocardial infarction to enhance bone marrow stem cell mobilization in humans: Clinical and angiographic safety profile. Eur Heart J 26: 1838-1845, 2005.

6. Zohlnhöfer D, Ott I, Mehilli J, Schömig K, Michalk F, Ibrahim T, Meisetschläger G, von Wedel J, Bollwein H, Seyfarth M, et al: Stem cell mobilization by granulocyte colony-stimulating factor in patients with acute myocardial infarction: A randomized controlled trial. JAMA 295: 1003-1010, 2006.

7. Brunner S, Huber BC, Fischer R, Groebner M, Hacker M, David R, Zaruba MM, Vallaster M, Rischpler C, Wilke A, et al: G-CSF treatment after myocardial infarction: Impact on bone marrow-derived vs cardiac progenitor cells. Exp Hematol 36: 695-702, 2008

8. Hasegawa $\mathrm{H}$, Takano H, Iwanaga K, Ohtsuka M, Qin Y, Niitsuma Y, Ueda K, Toyoda T, Tadokoro H and Komuro I: Cardioprotective effects of granulocyte colony-stimulating factor in swine with chronic myocardial ischemia. J Am Coll Cardiol 47: 842-849, 2006.

9. Kagawa R, Moritake K, Shima T and Okada Y: Validity of B-mode ultrasonographic findings in patients undergoing carotid endarterectomy in comparison with angiographic and clinicopathologic features. Stroke 27: 700-705, 1996.

10. Handa N, Matsumoto M, Maeda H, Hougaku H, Ogawa S, Fukunaga R, Yoneda S, Kimura K and Kamada T: Ultrasonic evaluation of early carotid atherosclerosis. Stroke 21: 1567-1572, 1990.

11. Ripa RS, Jørgensen E, Wang Y, Thune JJ, Nilsson JC, Søndergaard L, Johnsen HE, Køber L, Grande P and Kastrup J: Stem cell mobilization induced by subcutaneous granulocyte-colony stimulating factor to improve cardiac regeneration after acute ST-elevation myocardial infarction: Result of the double-blind, randomized, placebo-controlled stem cells in myocardial infarction (STEMMI) trial. Circulation 113: 1983-1992, 2006.

12. Powell TM, Paul JD, Hill JM, Thompson M, Benjamin M, Rodrigo M, McCoy JP, Read EJ, Khuu HM, Leitman SF, et al: Granulocyte colony-stimulating factor mobilizes functional endothelial progenitor cells in patients with coronary artery disease. Arterioscler Thromb Vasc Biol 25: 296-301, 2005.

13. Hill JM, Syed MA, Arai AE, Powell TM, Paul JD, Zalos G, Read EJ, Khuu HM, Leitman SF, Horne M, et al: Outcomes and risks of granulocyte colony-stimulating factor in patients with coronary artery disease. J Am Coll Cardiol 46: 1643-1648, 2005.

14. Kang HJ, Lee HY, Na SH, Chang SA, Park KW, Kim HK, Kim SY, Chang HJ, Lee W, Kang WJ, et al: Differential effect of intracoronary infusion of mobilized peripheral blood stem cells by granulocyte colony-stimulating factor on left ventricular function and remodeling in patients with acute myocardial infarction versus old myocardial infarction: The MAGIC Cell-3-DES randomized, controlled trial. Circulation 114 (1 Suppl): I145-I151, 2006.

15. Tse G, Hothi SS, Grace AA and Huang CL: Ventricular arrhythmogenesis following slowed conduction in heptanol-treated, Langendorff-perfused mouse hearts. J Physiol Sci 62: 79-92, 2012.

16. Tse G, Tse V, Yeo JM and Sun B: Atrial anti-arrhythmic effects of heptanol in Langendorff-perfused mouse hearts. PLoS One 11: e0148858, 2016. 
17. Tse G, Yeo JM, Tse V and Sun B: Gap junction inhibition by heptanol increases ventricular arrhythmogenicity by decreasing conduction velocity without affecting repolarization properties or myocardial refractoriness in Langendorff-perfused mouse hearts. Mol Med Rep 14: 4069-4074, 2016.

18. Tse G, Wong ST, Tse V and Yeo JM: Restitution analysis of alternans using dynamic pacing and its comparison with S1S2 restitution in heptanol-treated, hypokalaemic Langendorff-perfused mouse hearts. Biomed Rep 4: 673-680, 2016.

19. Tse G, Tse V and Yeo JM: Ventricular anti-arrhythmic effects of heptanol in hypokalaemic, Langendorff-perfused mouse hearts. Biomed Rep 4: 313-324, 2016.

20. Tse G, Sun B, Wong ST, Tse V and Yeo JM: Anti-arrhythmic effects of hypercalcemia in hyperkalemic, Langendorff-perfused mouse hearts. Biomed Rep 5: 301-310, 2016.

21. Choy L, Yeo JM, Tse V, Chan SP and Tse G: Cardiac disease and arrhythmogenesis: Mechanistic insights from mouse models. Int J Cardiol Heart Vasc 12: 1-10, 2016.

22. Tse G, Wong ST, Tse V, Lee YT, Lin HY and Yeo JM: Cardiac dynamics: Alternans and arrhythmogenesis. J Arrhythm 32: 411-417, 2016.

23. Tse G, Lai ET, Yeo JM and Yan BP: Electrophysiological mechanisms of Bayés syndrome: Insights from clinical and mouse studies. Front Physiol 7: 188, 2016.

24. Tse G,LaiET,Lee AP, Yan BP and Wong SH: Electrophysiological mechanisms of gastrointestinal arrhythmogenesis: Lessons from the heart. Front Physiol 7: 230, 2016.

25. Tse G,Fiona Chan YW,Keung W and Yan BP: Electrophysiological mechanisms of long and short QT syndromes: Insights from mouse models. Int J Cardiol Heart Vasc 14: 8-13, 2017.

26. Tse G, Lai TH, Yeo JM, Tse V and Wong SH: Mechanisms of electrical activation and conduction in the gastrointestinal system: Lessons from cardiac electrophysiology. Front Physiol 7: $182,2016$.

27. Tse G, Lai ET, Tse V and Yeo JM: Molecular and electrophysiological mechanisms underlying cardiac arrhythmogenesis in diabetes mellitus. J Diabetes Res 2016: 2848759, 2016.

28. Tse G, Yan BP, Chan YW, Tian XY and Huang Y: Reactive oxygen species, endoplasmic reticulum stress and mitochondrial dysfunction: The link with cardiac arrhythmogenesis. Front Physiol 7: 313, 2016.

29. Chen Z, Sun B, Tse G, Jiang J and Xu W: Reversibility of both sinus node dysfunction and reduced HCN4 mRNA expression level in an atrial tachycardia pacing model of tachycardia-bradycardia syndrome in rabbit hearts. Int J Clin Exp Pathol 9: 8526-8531, 2016

30. Tse G, Yeo JM, Chan YW, Lai ET and Yan BP: What is the arrhythmic substrate in viral myocarditis? Insights from clinical and animal studies. Front Physiol 7: 308, 2016.

31. Tse G and Yeo JM: Conduction abnormalities and ventricular arrhythmogenesis: The roles of sodium channels and gap junctions. Int J Cardiol Heart Vasc 9: 75-82, 2015.

32. Tse G: Mechanisms of cardiac arrhythmias. J Arrhythm 32 75-81, 2016.

33. Vassiliou V, Chin C, Perperoglou A, Tse G, Ali A, Raphael C, Jabbour A, Newby D, Pennell D, Dweck M and Prasad S: 93 ejection fraction by cardiovascular magnetic resonance predicts adverse outcomes post aortic valve replacement. Heart 100 (Suppl 3): A53-A54, 2014.

34. Tse G, Ali A, Prasad SK, Vassiliou V and Raphael CE: Atypical case of post-partum cardiomyopathy: An overlap syndrome with arrhythmogenic right ventricular cardiomyopathy? BJR Case Rep 1: 20150182, 2015.

35. Tse G, Ali A, Alpendurada F, Prasad S, Raphael CE and Vassiliou V: Tuberculous constrictive pericarditis. Res Cardiovasc Med 4: e29614,2015.

36. Tse G: Both transmural dispersion of repolarization and of refractoriness are poor predictors of arrhythmogenicity: A role for iCEB (QT/QRS)? J Geriatr Cardiol 13: 813-814, 2016.

37. Tse G, Wong ST, Tse V and Yeo JM: Monophasic action potential recordings: Which is the recording electrode? J Basic Clin Physiol Pharmacol 27: 457-462, 2016.

38. Tse G and Yan BP: Novel arrhythmic risk markers incorporating QRS dispersion: $\mathrm{QRS}_{\mathrm{d}} \mathrm{x}\left(\mathrm{T}_{\text {peak }}-\mathrm{T}_{\text {end }}\right) / \mathrm{QRS}$ and $\mathrm{QRS}_{\mathrm{d}} \mathrm{x}$ $\left(\mathrm{T}_{\text {peak }}-\mathrm{T}_{\text {end }}\right) /(\mathrm{QT} \times \mathrm{QRS})$. Ann Noninvasive Electrocardiol 22: Nov, 2016 (doi: 10.1111/anec.12397)

39. Tse G: Novel conduction-repolarization indices for the stratification of arrhythmic risk. J Geriatr Cardiol 13: 811-812, 2016.

40. Tse G: (Tpeak-Tend)/QRS and (Tpeak-Tend)/(QT x QRS): Novel markers for predicting arrhythmic risk in Brugada syndrome. Europace 19: 696, 2017
41. Tse G and Yan BP: Traditional and novel electrocardiographic markers for predicting arrhythmic risk and sudden cardiac death. Europace 19: 712-721, 2016.

42. Tse G, Wong ST, Tse V and Yeo JM: Depolarization vs. repolarization: What is the mechanism of ventricular arrhythmogenesis underlying sodium channel haploinsufficiency in mouse hearts? Acta Physiol (Oxf) 218: 234-235, 2016.

43. Tse G, Wong ST, Tse V and Yeo JM: Variability in local action potential durations, dispersion of repolarization and wavelength restitution in aged wild-type and Scn5 $\mathrm{a}^{+/-}$mouse hearts modelling human Brugada syndrome. J Geriatr Cardiol 13: 930-931, 2016.

44. Tse G, Wong ST, Tse V and Yeo JM: Determination of action potential wavelength restitution in $\mathrm{Scn} 5 \mathrm{a}^{+/-}$mouse hearts modelling human Brugada syndrome. J Physiol 14: 595-596, 2017.

45. Murugan D, Lau YS, Lau WC, Mustafa MR and Huang Y: Angiotensin 1-7 protects against angiotensin II-induced endoplasmic reticulum stress and endothelial dysfunction via mas receptor. PLoS One 10: e0145413, 2015.

46. Wei LH, Huang XR, Zhang Y, Li YQ, Chen HY, Heuchel R, Yan BP, Yu CM and Lan HY: Deficiency of Smad7 enhances cardiac remodeling induced by angiotensin II infusion in a mouse model of hypertension. PLoS One 8: e70195, 2013.

47. Wong WT, Tian XY and Huang Y: Endothelial dysfunction in diabetes and hypertension: Cross talk in RAS, BMP4, and ROS-dependent COX-2-derived prostanoids. J Cardiovasc Pharmacol 61: 204-214, 2013.

48. Ma S, Tian XY, Zhang Y, Mu C, Shen H, Bismuth J, Pownall HJ, Huang Y and Wong WT: E-selectin-targeting delivery of microRNAs by microparticles ameliorates endothelial inflammation and atherosclerosis. Sci Rep 6: 22910, 2016.

49. Lin Z, Pan X, Wu F, Ye D, Zhang Y, Wang Y, Jin L, Lian Q, Huang Y, Ding H, et al: Fibroblast growth factor 21 prevents atherosclerosis by suppression of hepatic sterol regulatory element-binding protein-2 and induction of adiponectin in mice. Circulation 131: 1861-1871, 2015.

50. Yuen CY, Wong SL, Lau CW, Tsang SY, Xu A, Zhu Z, Ng CF, Yao X, Kong SK, Lee HK and Huang Y: From skeleton to cytoskeleton: Osteocalcin transforms vascular fibroblasts to myofibroblasts via angiotensin II and toll-like receptor 4. Circ Res 111: e55-e66, 2012.

51. Zhang H, Liu J, Qu D, Wang L, Luo JY, Lau CW, Liu P, Gao Z, Tipoe GL, Lee HK, et al: Inhibition of miR-200c restores endothelial function in diabetic mice through suppression of COX-2. Diabetes 65: 1196-1207, 2016.

52. Cheang WS, Tian XY, Wong WT, Lau CW, Lee SS, Chen ZY, Yao X, Wang N and Huang Y: Metformin protects endothelial function in diet-induced obese mice by inhibition of endoplasmic reticulum stress through 5'adenosine monophosphate-activated protein kinase-peroxisome proliferator-activated receptor $\delta$ pathway. Arterioscler Thromb Vasc Biol 34: 830-836, 2014.

53. Morrow JP, Katchman A, Son NH, Trent CM, Khan R, Shiomi T, Huang H, Amin V, Lader JM, Vasquez C, et al: Mice with cardiac overexpression of peroxisome proliferator-activated receptor $\gamma$ have impaired repolarization and spontaneous fatal ventricular arrhythmias. Circulation 124: 2812-2821, 2011

54. Xie L, Feng H, Li S, Meng G, Liu S, Tang X, Ma Y, Han Y, Xiao Y, Gu Y, et al: SIRT3 mediates the antioxidant effect of hydrogen sulfide in endothelial cells. Antioxid Redox Signal 24: 329-343, 2016

55. $\mathrm{Xu} \mathrm{A}$ and Huang $\mathrm{Y}$ : A tireless giant in vascular research. J Cardiovasc Pharmacol 67: 359-360, 2016.

56. Chen Y, Liu J, Zheng Y, Wang J, Wang Z, Gu S, Tan J, Jing Q and Yang $\mathrm{H}$ : Uncoupling protein 3 mediates $\mathrm{H}_{2} \mathrm{O}_{2}$ preconditioning-afforded cardioprotection through the inhibition of MPTP opening. Cardiovasc Res 105: 192-202, 2015.

57. Zhang Y, Liu J, Luo JY, Tian XY, Cheang WS, Xu J, Lau CW, Wang L, Wong WT, Wong CM, et al: Upregulation of angiotensin (1-7)-mediated signaling preserves endothelial function through reducing oxidative stress in diabetes. Antioxid Redox Signal 23: 880-892, 2015

58. Li Y, Fukuda N, Yokoyama S, Kusumi Y, Hagikura K, Kawano T, Takayama T, Matsumoto T, Satomi A, Honye J, et al: Effects of $\mathrm{G}-\mathrm{CSF}$ on cardiac remodeling and arterial hyperplasia in rats. Eur J Pharmacol 549: 98-106, 2006.

59. Hansson GK: Immune mechanisms in atherosclerosis. Arterioscler Thromb Vasc Biol 21: 1876-1890, 2001. 
60. Haghighat A, Weiss D, Whalin MK, Cowan DP and Taylor WR: Granulocyte colony-stimulating factor and granulocyte macrophage colony-stimulating factor exacerbate atherosclerosis in apolipoprotein E-deficient mice. Circulation 115: 2049-2054, 2007.

61. Hasegawa H, Takano H, Ohtsuka M, Ueda K, Niitsuma Y, Qin Y, Tadokoro H, Shiomi M and Komuro I: G-CSF prevents the progression of atherosclerosis and neointimal formation in rabbits. Biochem Biophys Res Commun 344: 370-376, 2006.

62. Cho HJ, Kim TY, Cho HJ, Park KW, Zhang SY, Kim JH, Kim SH, Hahn JY, Kang HJ, Park YB and Kim HS: The effect of stem cell mobilization by granulocyte-colony stimulating factor on neointimal hyperplasia and endothelial healing after vascular injury with bare-metal versus paclitaxel-eluting stents. J Am Coll Cardiol 48: 366-374, 2006.

63. Kong D, Melo LG, Gnecchi M, Zhang L, Mostoslavsky G, Liew CC, Pratt RE and Dzau VJ: Cytokine-induced mobilization of circulating endothelial progenitor cells enhances repair of injured arteries. Circulation 110: 2039-2046, 2004.

64. Sehara Y,Hayashi T, Deguchi K,Zhang H, Tsuchiya A, Yamashita T, Lukic V, Nagai M, Kamiya T and Abe K: G-CSF enhances stem cell proliferation in rat hippocampus after transient middle cerebral artery occlusion. Neurosci Lett 418: 248-252, 2007.
65. Sato T, Suzuki H, Kusuyama T, Omori Y, Soda T, Tsunoda F, Shoji M, Iso Y, Koba S, Geshi E, et al: G-CSF after myocardial infarction accelerates angiogenesis and reduces fibrosis in swine. Int J Cardiol 127: 166-173, 2008.

66. Ripa RS, Wang Y, Jørgensen E, Johnsen HE, Hesse B and Kastrup J: Intramyocardial injection of vascular endothelial growth factor-A165 plasmid followed by granulocyte-colony stimulating factor to induce angiogenesis in patients with severe chronic ischaemic heart disease. Eur Heart J 27: 1785-1792, 2006.

67. Lim SY, Kim YS, Ahn Y, Jeong MH, Rok LS, Kim JH, Kim KH, Park HW, Kim W, Cho JG, et al: The effects of granulocyte-colony stimulating factor in bare stent and sirolimus-eluting stent in pigs following myocardial infarction. Int J Cardiol 118: 304-311, 2007. Attribution 4.0 International (CC BY 4.0) License. 